\title{
Electrocardiographic Changes and False-Positive Troponin I in a Patient with Acute Cholecystitis
}

\author{
Marco Stefano Demarchi Luca Regusci Fabrizio Fasolini \\ Department of Surgery, Ospedale Beata Vergine, Mendrisio, Switzerland
}

\section{Key Words}

Acute cholecystitis - Electrocardiographic changes - ST elevation - Rise in troponin

\begin{abstract}
Cardiac troponins are the most sensitive and specific serum markers of myocardial cell injury, but they can also arise without apparent cardiac injury. Besides, acute cholecystitis may be associated with nonspecific ST-T wave changes in electrocardiography (ECG). The signs and symptoms of gallbladder and heart disease may overlap, which can make diagnosis difficult. We describe the case of a 75-year-old woman with clinical features suggestive of acute cholecystitis associated with transient ST segment elevation and elevated troponin I that, after extensive workup, did not seem to be attributable to myocardial ischemia or any other acute cardiac problem, but were exclusively related to cholecystitis. We show that cholecystitis with gallbladder distension can be the sole cause of pathological ECG changes and an increased troponin I level; this should be considered when evaluating patients with similar presentations.
\end{abstract}

\section{Introduction}

Acute cholecystitis refers to a syndrome of right upper quadrant pain, fever and leukocytosis associated with gallbladder inflammation that is usually related to gallstone disease. Patients with acute cholecystitis typically complain of abdominal pain, most commonly in the right upper quadrant or epigastrium. The pain may radiate to the right shoulder or back. Associated complaints include nausea, vomiting and anorexia. A variety of other conditions can give rise to symptoms in the upper abdomen, which may be confused with acute cholecystitis. These include cardiac ischemia, which can usually be differentiated by the clinical setting in which it occurs and by obtaining the appropriate diagnostic studies, such as an electrocardiography (ECG) and laboratory examinations. However, acute cholecystitis has also been reported to mimic the nonspecific diffuse ECG changes associated with ischemic heart 
disease. This association and its pathophysiological mechanisms are poorly understood. Studies have shown that gallbladder distension reduces coronary blood flow, providing a mechanism for the association of gallbladder disease, myocardial ischemia and ST segment ECG changes. Various sources have also reported elevated troponin levels in patients with sepsis, septic shock or systemic inflammatory response syndrome, but the mechanism by which infection causes troponin release is not yet understood. The finding of ECG changes, associated with elevation of the specific cardiac marker troponin, alarms many physicians and leads them to initiate diagnostic cardiac investigations for early confirmation and treatment of ischemic heart disease. Awareness of the differential diagnosis is crucial to ensure appropriate diagnostic investigations and to avoid incorrect cardiac management, such as thrombolysis and even angioplasty.

\section{Case Report}

We present the case of a 75-year-old woman who presented at the accident and emergency department after 2 days of epigastric and right upper quadrant pain associated with nausea but without fever. She had been referred for nonspecific digestive difficulties within the past few months and for a similar episode 1 week earlier. Cardiorespiratory examination was unremarkable, and she was hemodynamically stable. The abdomen was tender, with guarding in the right upper quadrant and positive Murphy's sign. Abdominal ultrasound revealed gallbladder distension, wall thickening and a $2.5 \mathrm{~cm}$ stone in the gallbladder lumen that were suggestive of acute cholecystitis (fig. 1 ). No pericholecystic fluid or intrahepatic and extrahepatic ductal dilatation was observed. The following laboratory findings were obtained at admission: white blood cell count $8.3 \times 10^{9} / \mathrm{l}$, C-reactive protein (CRP) $85 \mathrm{mg} / \mathrm{l}$, serum total bilirubin $17.3 \mu \mathrm{mol} / \mathrm{l}$, alkaline phosphatase $79 \mathrm{IU} / \mathrm{l}$, aspartate aminotransferase $23 \mathrm{IU} / \mathrm{l}$; alanine aminotransferase $29 \mathrm{IU} / \mathrm{l}$, lipase $32 \mathrm{IU} / \mathrm{l}$, sodium $136 \mathrm{mmol} / \mathrm{l}$, potassium $3.8 \mathrm{mmol} / \mathrm{l}$, blood urea $5.1 \mathrm{mmol} / \mathrm{l}$, creatinine $82 \mu \mathrm{mol} / \mathrm{l}$ and troponin $\mathrm{I}<0.01 \mathrm{U} / \mathrm{l}$. The clinical diagnosis was acute cholecystitis. ECG showed sinus rhythm with an incomplete right branch block and negative T waves in V1-V3 with no sign of ischemia (results comparable to previous ECG).

The patient was initially managed with intravenous antibiotics (cephalosporin and metronidazole) and fluids. Approximately $24 \mathrm{~h}$ after admission, she developed fever $\left(39^{\circ} \mathrm{C}\right)$. Two peripheral blood cultures were taken, but the results were negative. Hematological and biochemical investigations revealed an increased white blood cell count $\left(10.2 \times 10^{9} / \mathrm{l}\right)$ and a CRP of $434 \mathrm{mg} / \mathrm{l}$, with normal urea, electrolytes, liver function, amylase and bilirubin. Based on the deteriorating laboratory values, we planned a surgical cholecystectomy. Despite the absence of chest pain, we performed further preoperative ECG on the advice of the anesthetist. ECG showed ST segment depression in V3 in addition to the already known negative T waves in V1-V3. In view of these unexpected ECG findings, cardiac marker levels were checked. The troponin I level was elevated $(0.78 \mu \mathrm{g} / \mathrm{l})$ and the creatine kinase level was $409 \mathrm{U} / \mathrm{l}$. The patient was initially managed conservatively using the acute coronary syndrome protocol for anticoagulation with high-dose low-molecular-weight heparin, aspirin and $\beta$-blockers in addition to the already administered angiotensin-converting enzyme inhibitors. The patient was admitted to the intensive care unit for monitoring. The troponin level decreased to $0.49 \mu \mathrm{g} / \mathrm{l}$ after $12 \mathrm{~h}$ and to $0.30 \mu \mathrm{g} / \mathrm{l}$ after another $8 \mathrm{~h}$.

Cardiac ultrasound showed a mildly enlarged right ventricle, no enlargement of the left ventricle, a good ejection fraction and a right overload septal motion abnormality with pulmonary hypertension (systolic peripheral arterial pressure $\sim 45-50 \mathrm{~mm} \mathrm{Hg}$ ). An angio-CT was performed to exclude pulmonary embolism; the findings were negative. Coronary angiography was then undertaken, showing no abnormality and normal left ventricular function. Finally, abdominal CT confirmed cholecystitis and excluded empyema or abscess complications (fig. 2).

The clinical course was favorable, with a progressive disappearance of abdominal symptoms and a return to normal complete blood count, lipase, cardiac markers, electrolytes, bilirubin aminotransferase and CRP levels. The patient was discharged with instructions for elective surgery for symptomatic cholelithiasis. 


\section{Discussion}

In previous studies, gallbladder distension has been associated with nonspecific T-wave inversions or ST segment depressions that are similar to those of ischemic heart disease [1-4], and only five previous cases with similar ischemic ECG changes attributed to cholecystitis have been reported [5-9]. Several studies in animals [10,11] have demonstrated that gallbladder distension can reduce coronary blood flow and increase heart rate and arterial blood pressure, and may explain the association with transiently mimicked myocardial ischemia and ST segment ECG changes.

Increases in troponin are most commonly related to ischemic myocardial cell injury/necrosis, but nonischemic cardiac causes include prolonged tachycardia and septicemia/septic shock $[12,13]$. Only two previous reports $[14,15]$ have described increased troponin levels in a patient with acute cholecystitis; the simultaneous presentation of both pathological findings has not been reported.

The new finding in this case was the observation of ECG changes that mimicked myocardial infarction, with a raised troponin I level that did not seem to be attributable to myocardial ischemia, but was exclusively related to cholecystitis. This case shows that cholecystitis with gallbladder distension can be the sole cause of pathological ECG changes and an increased troponin I level, which should be considered when evaluating patients with similar presentations.

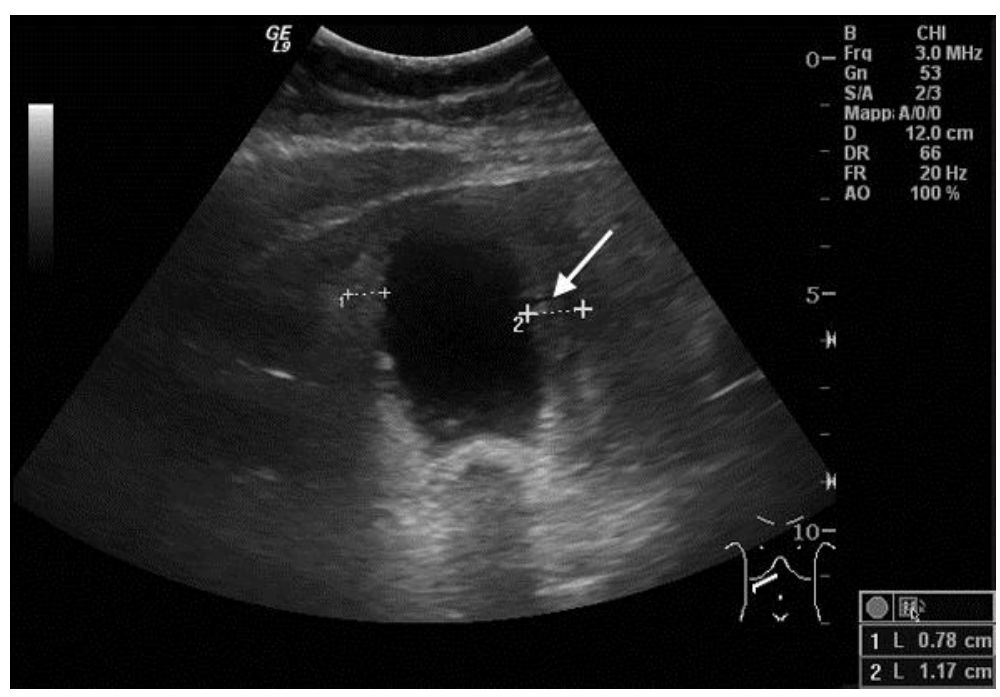

Fig. 1. Ultrasound findings: gallbladder distension and $1.17 \mathrm{~cm}$ wall thickening (arrow). 


\begin{tabular}{l|l|l|l}
$\begin{array}{r}\text { Case Reports in } \\
\text { Gastroenterology }\end{array}$ & $\begin{array}{l}\text { Case Rep Gastroenterol 2012;6:410-414 } \\
\text { DOI: 10.1159/000339965 }\end{array}$ & $\begin{array}{l}\text { Published online: } \\
\text { June 26, 2012 }\end{array}$ & $\begin{array}{l}\text { @ 2012 S. Karger AG, Basel } \\
\text { ISSN 1662-0631 } \\
\text { www.karger.com/crg }\end{array}$ \\
\hline
\end{tabular}

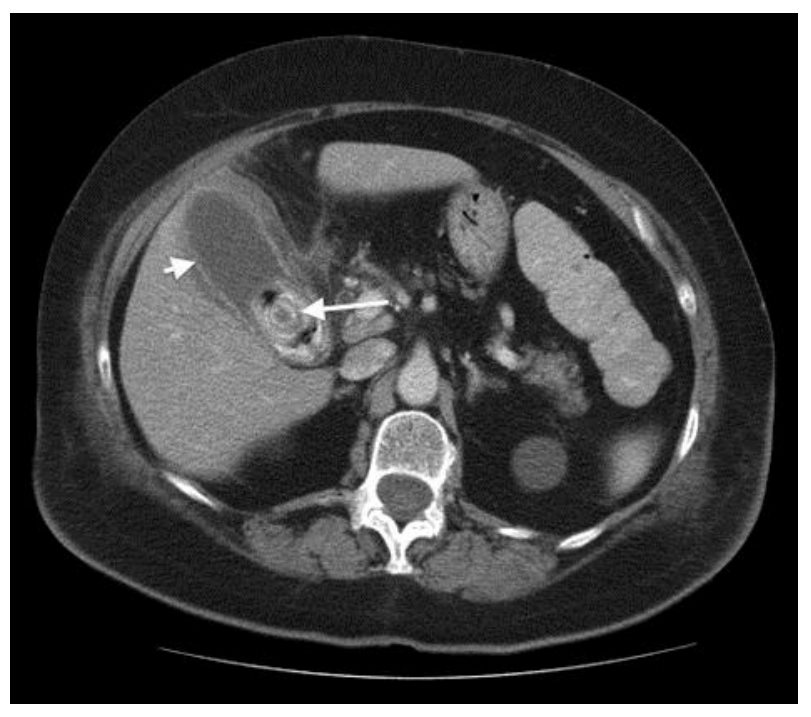

Fig. 2. Abdominal CT image showing gallbladder distension, wall thickening (short arrow) and a $2.5 \mathrm{~cm}$ stone in the gallbladder lumen (long arrow). This excluded empyema or abscess complications.

\section{References}

$\checkmark 1$ Faintuch J, Silva MM, Faintuch JJ, Machado MC, Raia AA: Electrocardiographic changes in acute cholecystitis (in Portuguese). Rev Hosp Clin Fac Med Sao Paulo 1982;37:17-20.

-2 Krasna MJ, Flancbaum L: Electrocardiographic changes in cardiac patients with acute gallbladder disease. Am Surg 1986;52:541-543.

3 Dickerman JL: Electrocardiographic changes in acute cholecystitis. J Am Osteopath Assoc 1989;89: 630-635.

-4 Ryan ET, Pak PH, DeSanctis RW: Myocardial infarction mimicked by acute cholecystitis. Ann Intern Med 1992;116:218-220.

5 Furuhashi M, Uno K, Satoh S, Hoshikawa K, Sakai E, Tsuchihashi K, Shimamoto K: Right bundle branch block and coved-type ST-segment elevation mimicked by acute cholecystitis. Circ J 2003;67:802-804.

-6 Franzen D, Jung S, Fatio R, Brunckhorst CB: Complete atrioventricular block in a patient with acute cholecystitis: a case of cardio-biliary reflex? Eur J Emerg Med 2009;16:346-347.

7 Aksay E, Ersel M, Kiyan S, Musalar E, Gungor H: Acute coronary syndrome mimicked by acute cholecystitis. Emerg Med Australas 2010;22:343-346.

-8 Seewoodhary J, Griffin L: Trifascicular block and a raised Troponin 'T' in acute cholecystitis. QJM 2010;103:121-123.

9 Patel N, Ariyarathenam A, Davies W, Harris A: Acute cholecystitis leading to ischemic ECG changes in a patient with no underlying cardiac disease. JSLS 2011;15:105-108.

10 Ordway GA, Longhurst JC: Cardiovascular reflexes arising from the gallbladder of the cat. Effects of capsaicin, bradykinin, and distension. Circ Res 1983;52:26-35.

11 Vacca G, Battaglia A, Grossini E, Mary DA, Molinari C: Reflex coronary vasoconstriction caused by gallbladder distension in anesthetized pigs. Circulation 1996;94:2201-2209. 
12 Terradellas JB, Bellot JF, Saris AB, Gil CL, Torrallardona AT, Garriga JR: Acute and transient ST segment elevation during bacterial shock in seven patients without apparent heart disease. Chest 1982;81:444-448.

-13 Burness CE, Beacock D, Channer KS: Pitfalls and problems of relying on serum troponin. QJM 2005;98: 365-371.

$\checkmark 14$ Banerjee S, Linder MW, Singer I: False-positive troponin I in a patient with acute cholecystitis and positive rheumatoid factor assay. Cardiology 2001;95:170-171.

15 Fox DJ, Grimm C, Curzen NP: Raised troponin T in acute cholecystitis. J R Soc Med 2004;97:179. 